\title{
EFFECT OF PARIS SAPONIN ON ANTITUMOR AND IMMUNE FUNCTION IN U14 TUMOR-BEARING MICE
}

\author{
Chen GuangLie ${ }^{1}$, Gao WeiShi ${ }^{2}$, Hou GaiLing ${ }^{3}$, Cao JianPing ${ }^{{ }^{*}}$
}

${ }^{1}$ School of Radiation Medicine and Protection, Medical College of Soochow University, Suzhou, Jiangsu Province, China. 215123, 2 Surgical oncology, Inner Mongolia Autonomous Region Hospita, Hohhot, Inner Mongolia,China.010050, ${ }^{3}$ Medicament department, Inner Mongolia tongliao city hospital ,Tongliao, Inner Mongolia, China.028000

*E-mail: cglie2012@yeah.com

\begin{abstract}
We evaluated the effect of Paris saponin on inhibition of cervical cancer in mice and on immune regulation in tumor-bearing mice. MTT assay was used to examine the effect of Paris saponin on U14 cell proliferatiosn in vitro; the ascites tumor model of U14 cervical cancer was established to observe the effect of Paris saponin on inhibition of the tumor and on survival time of mice; and serum IL-4 and IFN- $\gamma$ levels in tumor-bearing mice were detected. The Paris saponin showed significant inhibitory effect on growth of cervical cancer U14 cells both in vitro and in vivo, prolonged the survival time of mice, increased the serum IFN- $\gamma$ level of tumor-bearing mice, and reduced the serum IL-4 level. The Paris saponin can inhibit U14 cell growth and prolong survival time of mice; it is speculated that the Paris saponin may express its anti-tumor activity by improving the body's immune system.
\end{abstract}

Key words: Paris saponin, antitumor, cytokine

\section{Introduction}

Rhizoma Paridis is the dried rhizome of Paris polyphylla Smith var. yunnanensis (Franch.) Hand.-Mazz. or Paris polyphylla Smith var. chinensis (Franch.) Hara, which belongs to the Liliaceae plant family (Chinese Pharmacopoeia Commission,. 2010). It is bitter, slightly cold, mildly toxic, and can clear heat and remove toxicity, relieve swelling and pain, cool the liver and arrest convulsion. Pharmacological studies have found that its active ingredients have the haemostatic effect (Fu, 2007), anti-tumor effect (Liu, 2008), antibacterial effect (Li, 2009), anti-inflammatory effect (Zhang, 2008), brain and kidney protection effect (Huang, 2008), antioxidant effect (Gao, 2007), and uterine contraction effect (Cong, 2005). At present, the chemical constituents extracted from Rhizoma Paridis are mainly steroidal saponins and free amino acids, of which Paris saponins account for approximately $80 \%$ of the total number of compounds, most of them are diosgenin, which is an active anti-tumor ingredient, including Paris saponin I (diosgenin 3-O- $\alpha$-L-rha-(1-2)-[ $\alpha$-L-arab-(1-4)]- $\beta$-D-glu),Paris saponin II (diosgenin3-O- $\alpha$-rha-(1-4)- $\alpha$-L-rha-(1-4)-[ $\alpha$-L-rha-(1-2)]- $\beta$-D-

glu), Paris saponin III, diosgenin and C22-hydroxy-protodioscin, C22-methoxy-protodioscin, C22-hydroxy-protopolyphyllin I, C22-methoxy-protopolyphyllin I, C22-methoxy- protopolyphyllin II, etc. (Wu., 2004). Isolated PSII has potent inhibitory effects on the growth of tumor cells without deleterious effects on different normal cell types or benign neoplastic derived cells. (Xiao et al., 2012).

\section{Materials and methods}

Medicinal materials

Rhizoma Paridis was purchased from Dalian Baidu Pharmaceutical Company. 
http://dx.doi.org/10.4314/ajtcam.v10i3.17

\section{Apparatuses and reagents}

Refrigerated centrifuge (Eppendorf, Germany), clean bench (Suzhou Purification Equipment Co., Ltd.), $\mathrm{CO}_{2}$ incubator (SANYO, Japan), continuous wavelength microplate reader (Bio-RAD), electronic balance (Shanghai Precision Instrument Co., Ltd.), IFN- $\gamma$ and IL-4 ELISA test kit (purchased from Nanjing Jiancheng Reagent Company), MTT (purchased from Sigma-Aldrich Corp), cyclophosphamide (purchased from Jiangsu Hengrui Medicine Co., Ltd.)

\section{Cell lines and experimental animals}

Cervical cancer cell lines (U14) was purchased from the Chinese Academy of Medical Sciences. Female Kunming mice weighing $18 \pm 2 \mathrm{~g}$ were purchased from the Laboratory Animal Center of Dalian Medical University.

\section{Preparation of Paris saponin extract}

Referencing to the method of Zhu Li-li (Zhu., 2006), Rhizoma Paridis was soaked in a 10-fold amount of $70 \%$ ethanol overnight, and extracted three times with heat reflux extraction at $88{ }^{\circ} \mathrm{C}$ for 4 hours, the filtrates were combined and ethanol was recovered, then they were dried in vacuo and Rhizoma Paridis total saponins were obtained.

\section{In vitro experiment}

The intraperitoneally passaged ascites were extracted from mice under sterile conditions using MTT assay, dispersed into single cell suspension using culture solution, seeded in a 96-well plate with $100 \mu \mathrm{l}$ each well, and cultured for 24 hours. Culture solution was discarded, and drug-containing culture medium was added (three replicate wells for each drug concentration). Meanwhile, blank control group which was only added with the complete culture solution was set up. After culturing in a $37^{\circ} \mathrm{C}$ incubator with $5 \% \mathrm{CO}_{2}$ and saturated humidity for $48 \mathrm{~h}$ and $72 \mathrm{~h}$, each well was added with $20 \mu \mathrm{L}$ of MTT solution, the culturing was continued for an additional $4 \mathrm{~h}$, then the supernatant was discarded. $150 \mu \mathrm{L}$ of DMSO was added to each well, and the plate was shaken in a micromixer for $10 \mathrm{~min}$, after the crystalline particles were fully dissolved, absorbance value (A value) of each hole was measured at $490 \mathrm{~nm}$, and the growth inhibition rate (IR) was calculated according to the following formula:Cell growth inhibition rate $(\%)=(1$ - average A value of drug group / average A value of control group) $\times 100$.

\section{In vivo test ( $\mathrm{Li}$ et al, 2009)}

The intraperitoneally passaged ascites were extracted from mice under sterile conditions, the concentration of collected cells was adjusted to $1 \times 10^{6} / \mathrm{mL}$ using sterile saline solution, and $0.2 \mathrm{ml}$ was inoculated intraperitoneally into each mouse. 24 $\mathrm{h}$ after inoculation, the mice were weighed, grouped and administered; mice were randomly divided into 5 groups, with 10 mice in each group, they were negative control group, positive control group as well as Paris saponin high- and low-dose treatment groups respectively. Positive control group was administered by intraperitoneal injection of $20 \mathrm{mg} / \mathrm{kg}$ of cyclophosphamide according to body weight, negative control group was intragastrically administered normal saline, and Paris saponin high- and low-dose groups were intragastrically administered $100 \mathrm{mg} / \mathrm{kg}$ and $50 \mathrm{mg} / \mathrm{kg}$ of Paris saponin respectively according to body weight for 8 consecutive days. On the 9th day, mice were blood-sampled from eyeballs and sacrificed, ascites of each group were extracted, and the number of ascites tumor cells was counted. 


\section{http://dx.doi.org/10.4314/ajtcam.v10i3.17}

\section{IFN- $\gamma$ and IL-4 levels in serum of tumor-bearing mice}

Blood was sampled from eyeballs of mice in experimental groups and control groups, and centrifuged at 3000 $\mathrm{r} / \mathrm{min}$ for $20 \mathrm{~min}$, serum was collected, and IFN- $\gamma$ and IL-4 levels in serum of each group were measured according to kit instructions.

\section{Effect of Paris saponin on survival time of tumor-bearing mice}

Modeling and grouping method was as described above, after continuous administration for 15 days and drug withdrawal, survival time of mice in each group was recorded, and life prolongation rate was calculated according to the following formula.

Life prolongation rate $(\%)=[($ mean survival time of mice in drug treatment group - mean survival time of mice in negative control group) / mean survival time of mice in negative control group] $\times 100$.

\section{Statistical analysis}

The results obtained were analyzed using Origin 7.5 statistical software.

\section{Results}

The results for in-vitro inhibitory effect of Paris saponin on U14 cells are as follows. The results showed that different doses of Paris saponin $(5 \mu \mathrm{g} / \mathrm{ml}-80 \mu \mathrm{g} / \mathrm{ml})$ had inhibitory effect on U14 cells in vitro, in a concentration-dependent manner, inhibition rate increased with increasing of concentrations, at the same time, it also had certain time-dependency, which was significantly different $(\mathrm{p}<0.05)$ compared with the control group (Table 1$)$.

Table 1: Inhibitory effect of Paris saponin on U14 cells

\begin{tabular}{lll}
\hline & \multicolumn{2}{c}{ Treatment time $(\mathrm{h})$} \\
& 48 & 72 \\
$\begin{array}{l}\text { Concentration }(\mu \mathrm{g} / \mathrm{ml}) \\
\text { Control group }\end{array}$ & Inhibition rate $(\%)$ & Inhibition rate (\%) \\
\hline 5 & & \\
10 & 15.12 & 7.48 \\
20 & 24.75 & 31.41 \\
40 & 57.65 & 67.15 \\
80 & 67.47 & 74.55 \\
\hline
\end{tabular}

The results for in-vivo anti-tumor effect of Paric saponin in U14 ascites tumor bearing mice are shown in Table 2. The results showed that, after intragastric administration of different doses of Paris saponin in tumor-bearing mice, numbers of ascites tumor cells in mice were all significantly reduced, which were significantly different compared with the negative control group, indicating that Paris saponin had an anti-tumor effect in vivo.

Table 2: Effect of Paris saponin on inhibition of in-vivo ascites tumor growth $(\overline{\mathbf{X}} \pm \mathrm{S})$

\begin{tabular}{llllll}
\hline Group & Drug & Number of animals & Number of tumor & Inhibition \\
& concentration $(\mathrm{mg} / \mathrm{k}$ & Start & End & cells $\times 10^{8} \mathrm{cell} / \mathrm{ml}$ & rate $(\%)$ \\
\hline
\end{tabular}


http://dx.doi.org/10.4314/ajtcam.v10i3.17

g)

\begin{tabular}{|c|c|c|c|c|c|}
\hline Control group & Normal saline & 10 & 10 & $8.10 \pm 0.42$ & \\
\hline Cyclophosphamide & 20 & 10 & 10 & $2.72 \pm 0.34 * *$ & 66.4 \\
\hline \multirow[t]{2}{*}{ Paridis total saponins } & 50 & 10 & 10 & $4.78 \pm 0.24 * *$ & 41.0 \\
\hline & 100 & 10 & 10 & $3.91 \pm 0.56 * *$ & 51.7 \\
\hline
\end{tabular}

Note: Comparison with the negative control group, $* * \mathrm{P}<0.01$

The results for effect of Paris saponin on serum IFN- $\gamma$ and IL-4 levels in tumor-bearing mice are as follows (Table 3 ).

Table 3: Effect of Paris saponin on serum IFN- $\gamma$ and IL-4 levels in tumor-bearing mice $(\bar{X} \pm \mathrm{S})$

\begin{tabular}{llll}
\hline Group & $\begin{array}{l}\text { Drug concentration } \\
\mathrm{mg} / \mathrm{kg}\end{array}$ & $\begin{array}{l}\mathrm{IFN}-\gamma \\
\mathrm{pg} / \mathrm{ml}\end{array}$ & $\mathrm{IL}-4$ \\
\hline Control & Normal saline & $81.57 \pm 7.16$ & $\mathrm{pg} / \mathrm{ml}$ \\
Cyclophosphamide & 20 & $76.11 \pm 8.45$ & $13.84 \pm 2.74$ \\
Paris saponin & 50 & $61.71 \pm 6.78^{* *}$ & $14.94 \pm 2.96$ \\
& 100 & $47.36 \pm 7.15^{* *}$ & $21.57 \pm 2.89^{* *}$ \\
\hline
\end{tabular}

Note: Comparison with the negative control group, ${ }^{* *} P<0.01$

The results show that, compared with the negative control group, serum IFN- $\gamma$ level in mice of Paris saponin group significantly increased, while IL-4 level significantly decreased.

\section{Effect on survival time of mice}

Table 4: Effect of Paris saponin on survival time of tumor-bearing mice $(\bar{X} \pm \mathrm{S})$

\begin{tabular}{llclll}
\hline Group & $\begin{array}{l}\text { Drug } \\
\text { concentration }(\mathrm{mg} / \mathrm{kg})\end{array}$ & $\begin{array}{l}\text { Number } \\
\text { animals }\end{array}$ & $\begin{array}{l}\text { of } \\
\text { (Days) }\end{array}$ & $\begin{array}{l}\text { Life } \\
\text { rate } \\
(\%)\end{array}$ & prolongation \\
\hline Control & Normal saline & 10 & $14.4 \pm 1.8$ & - \\
Cyclophosphamide & 20 & 10 & $26.7 \pm 2.5^{* *}$ & 85.4 \\
Paris saponin & 50 & 10 & $19.6 \pm 1.9^{*}$ & 36.1 \\
Paris saponin & 100 & 10 & $23.4 \pm 2.0^{* *}$ & 62.5 \\
\hline
\end{tabular}

Comparison with the negative control group, ${ }^{*} P<0.05,{ }^{* *} P<0.01$

Compared with the negative control group, survival times of mice in cyclophosphamide group and Paris saponin group were significantly prolonged; mean survival times in Paris saponin groups were 19.6 \pm 1.9 and 23.4 $2.0 \mathrm{~d}$, and life prolongation rates were $36.1 \%$ and $62.5 \%$ respectively.

\section{Discussion}

The experimental results show that the Paris saponin had significant inhibitory effect on U14 cells in vitro, while in vivo, it could also significantly inhibit number of tumor cells in tumor-bearing mice; in addition, serum IFN- $\gamma$ level in mice was significantly increased, while IL-4 level was significantly reduced, thereby activating the immune cells to generate immune responses. It is probable that the tumor inhibition effect of Paris saponin is achieved via activation of immune factors in the body (Li., 2008). 
http://dx.doi.org/10.4314/ajtcam.v10i3.17

Many literatures have reported that the antitumor mechanism of Rhizoma Paridis may be through the inhibition of protein and DNA synthesis in tumor cells, inhibition of tumor cell mitosis, thereby inhibiting cell proliferation (Li., 2010), regulation of the body's immune (Bian et al, 2002) as well as induction of apoptosis and anti-angiogenesis (Lee et al, 2006; Shimizu et al, 2005; $\mathrm{Hu}$ et al, 2008). Rhizoma Paridis has complex chemical composition, and varied pharmacological effects, especially the tumor inhibition effect; clinical researches on active ingredients of Rhizoma Paridis should be carried out for the development and use of Rhizoma Paridis.

\section{References}

Bian H R. (2002). Advances in studies and applieations of Rhizoma Paridis. J.Chin.Med. Mater., 25(3):218-220.

2. Chinese Pharmacopoeia Commission. (2010). Pharmacopoeia of the People's Republic of China, Volume 1. China.Med.Sci.Press, Appendix 66.

3. Cong, Y.W., Ma, B.P. (2005). Study on Paris saponin-induced uterine smooth muscle contraction signaling pathway. Ninth National Academic Exchange Symposium on TCM Pharmacology, Guangzhou.

4. Fu, Y.L., Zhao, Z.H., Shan, Y.J., et al. (2007). Inducing effect of total steroid saponins from Paris polyphylla on platelet aggregation in vitro and its potential mechanism. Bulletin of the Academy of Military Medical Sciences., 31 (5): 416

5. Gao, Y.T., Yang, L.R, Yang, Y.L., et al. (2007). Study on in-vitro reactive oxygen scavenging activity of Rhizoma Paridis extract and its antioxidant effect. Chinese Traditional Patent Medicine., 29 (2): 195.

6. Hu, J., Qian, X.P., Liu, B.R., et al. (2008). The alcohol extracts of Paris Saponin's inhibition effect on the angiogenesis research. Journal of modern oncology, 16(8): 1273.

7. Huang, G.X., Liu, R.H. (2008). Effect of Rhizoma Paridis on nuclear transcription factor- $\kappa$ B activation and type IV collagen expression in membranous nephrotic rats. Chinese Journal of Integrated Traditional and Western Nephrology., 9 (1): 29.

8. Lee, T.J., Kim, E.J., Kim, S. et al. (2006). Caspase dependent and caspase independent apoptosis induced by evodiamine in human leukemic U937 cells. Mol.Cancer.Ther, 5(9):2398-2407.

9. Li, J., Han, Z.S., Li, Q.W. (2008). Study on Antitumor Activity and Immunomodulating Effect of Polysaccharides Isolated from Solanum nigrum Linne. Journal of Anhui Agricultural Sciences., 36 (33):14589-14590.

10. Liu, G.X., Wang, T.T., Hu, W.J., et al. (2008). Anticancer effect of Rhizoma Paridis on primary cancer cells isolated from malignant pleural effusion and ascites. Practical Geriatrics., $22(2): 101$.

11. Li, X., Wang, J.H., Xiao, Y.X. (2010). Effect of Rhizoma Paridis extract on human colon cancer SW480 cell proliferation and its mechanism. Chinese Journal of Biologicals., 23 (6): 601.

12. Li, Y.H., Liu, J., Yang, L.C., et al. (2009). Effects of Paris polyphylla var. yunnanensis on the growth of oral pathogens in vitro. Journal of Kunming Medical College., (11): 15.

13. Shimizu, K., Asai, T., Oku, N. (2005). Antineovascular therapy, a novel anti-angiogenic approach.Expert Opin Ther Targets, 2005,9(1):63-76.

14. Wu, S.S., Gao W.Y., Duan, H.Q., Jia Wei. (2004). Advances in studies on chemical constituents and pharmacological activities of Rhizoma Paridis. Chinese Traditional and Herbal Drugs., 35 (3).

15. Xiao X., Zou J., Bui-Nguyen T.M., Bai P., Gao L.B. et al. (2012). Paris Saponin II of Rhizoma Paridis-A novel inducer of apoptosis in human ovarian cancer cells. Biosci Trends. 6(4):201-11.

16. Zhang, X.L., Chen, A., Zeng, Z. (2008). Effect of Rhizoma Paridis on IgE level and eosinophil in rat asthma model. Chinese Journal of Difficult and Complicated Cases, 7 (9): 528.

17. Zhu, L.L. (2006). Optimization of Extraction Process for Rhizoma Paridis by Mass Trial and Study on Its Anti-tumor Mechanism. Master's degree thesis of Tianjin Medical University. 